\title{
Good CoPs and bad CoPs: facilitating reform in first-year assessment via a Community of Practice
}

\author{
Catherine Howlett, James Michael Arthur and Jo Anne Ferreira
}

School of Environment, Griffith University, Nathan, Australia

\begin{abstract}
The idea and implementation of learning communities are gaining favour in higher education institutions. In particular, there are a number of successful examples to emerge of the application of the Community of Practice (CoP) framework proposed by Wenger [(1998). Communities of practice: Learning, meaning, and identity. Cambridge, MA: Harvard Business School Press] for fostering a learning environment for academics around their teaching practice. In this paper, we describe and reflect on the efficacy of a $\mathrm{CoP}$ process that was implemented within our university. The purpose of this CoP was to provide a space for academics to focus on assessment practices for first-year courses and identify opportunities for professional development in this area. For a variety of reasons detailed in the paper, the efficacy of this CoP was limited, and we conclude that in the current higher education environment in Australia, success with CoP approaches to improve learning and teaching outcomes may prove limited.
\end{abstract}

\section{ARTICLE HISTORY}

Received 12 December 2014 Accepted 18 July 2015

\section{KEYWORDS}

Community of Practice; firstyear assessment; institutional change; professional development; retention

\section{Introduction}

Research on the first year in higher education continues to call for approaches that foster student engagement and retention through embedded and institution-wide change (Kift \& Nelson, 2005). The Academic Plan at our institution focuses squarely on transforming the student experience via a whole-of-institution approach that aims to provide an excellent student experience through co-curricular approaches (Griffith, 2013). This acknowledges the call by Kift, Nelson, and Clarke (2010) for institution-wide approaches to enhancing the first-year experience, and the work of Krause, Hartley, James, and McInnis (2005), who argued that effort must be directed at moving practice towards more holistic and sustainable institution-wide approaches. It is evident that our university is taking a whole-ofinstitution approach, with, for example, current teaching and learning grants squarely focused on fostering and enhancing opportunities for collegial approaches to learning and teaching.

In this current milieu, the Community of Practice ( $\mathrm{CoP})$ model appears appropriate as a strategy for facilitating change in this setting, with its approach to creating collaboration and development through voluntary actions across a particular domain (Wenger, 1998). CoPs are now widely regarded as a viable approach to enhance the teaching and learning 
practices of academics across a variety of settings in higher education (McDonald \& Star, 2006; Nagy \& Burch, 2009; Viskovic, 2006). With a focus on embedding change, the CoP process can engage academics in collaborative, professional conversations around identified issues as well as reflections on their teaching practice (McDonald \& Star, 2006; Richlin \& Cox, 2004).

There are, however, a number of unique challenges associated with the utilisation of CoPs in higher education. Such challenges include participation from academics that are increasingly overwhelmed by growing workloads and research output demands within changing institutional conditions (McDonald \& Star, 2006, 2008; Nagy \& Burch, 2009; Richlin \& Cox, 2004). This scenario is set to come under further pressure from changes to the higher education sector proposed by the current Australian Government, including deregulation of student fees and a reduction in government funding (Commonwealth of Australia, 2014). These cuts are expected to drive competition, impact retention and create inequality in learning opportunities and have therefore been received with concern by many in higher education (Riddle et al., 2014). Thus, societal pressures can affect the culture of the higher educational institutional setting in which the CoP is operating and ultimately affect the success of the $\mathrm{CoP}$ as an opportunity for learning about and improving teaching practice (see Ashwin, 2009).

Here, we describe, discuss and reflect on the use of a CoP to develop professional competency and coherency across assessment schedules for a cohort of first-year courses within our school (Wilson \& Lizzio, 2011). Assessment is now widely regarded as one of the most 'significant influences on students' experience of higher education' (Boud et al., 2010, p. 1) and thus reform and professional development in assessment design and practice is seen as pivotal to transforming the student experience. We seek to analyse the challenges that arose when employing the CoP model in times of institutional upheaval and flux characteristic of the current climate in higher education, and argue that structural and societal forces impacting on the culture of our institution, and higher education in general, ultimately rendered this CoP an unsuitable forum for professional development and learning around assessment reform.

The paper is structured in the following manner. First, we present a discussion on the issue of assessment and retention in the first-year space. We then present the rationale for utilising the CoP framework as an approach to addressing assessment reform. The design, management and implementation of the CoP are then described. We then present an analysis on the efficacy of this particular CoP. One of the key findings to emerge from interviews with $\mathrm{CoP}$ members was the constraints presented by the current institutional environment within the higher education sector in Australia, and thus we conclude the paper with a discussion of the constraints presented by the 'neoliberal turn' (see Curtis, 2013) in higher education in Australia and the implications of this for staff participation in, and learning from, CoPs.

\section{A focus on assessment and retention}

The effects of poorly planned assessment in higher education are well documented and include student disengagement from learning and the development of negative attitudes towards learning itself (Boud et al., 2010; Rust, 2002). As recent literature asserts, 'assessment drives the student experience' (Taylor, 2008, p. 20), and at a recent International 
Conference of the First Year Experience (Brisbane, 2012), the final keynote speaker, Professor Ron Oliver, presaged that assessment will be the key future focus in the provision of an excellent experience for first-year university students. Assessment is thus pivotal to the overall student experience of higher education and has obvious ramifications for student engagement and retention Oliver (2012).

The issue of the 'student experience' has been identified as a critical priority for Griffith University (Griffith University, 2013). This positive experience includes the provision of coherent curricular and co-curricular learning experiences and support that enable students' success. The explicit connection between assessment and the student experience, while recognised in the literature, was not, at the time of inception of the CoP in this case study, being addressed through any institutionally driven processes at our institution. This gap informed the development of a collaborative approach to reformation of the assessment practices across the first-year courses offered within our school. The authors successfully applied for an institutional Learning and Teaching grant to implement a CoP as a collaborative opportunity to improve and inform assessment practices. What follows is a review of the literature on CoPs that seeks to provide a coherent and critical appraisal of the potential for the utilisation of a CoP in such a setting, and which will be employed as a framework in the ensuing analysis.

\section{Communities of Practice}

CoPs are defined as 'groups of people who share a concern, a set of problems, or a passion about a topic, and who deepen their knowledge and expertise in this area by interacting on an ongoing basis' (Wenger, McDermott, \& Snyder, 2002, pp. 4-5). They are groups or networks which help guide, regulate and make meaning of both work and non-work situations (Tight, 2007, p. 398). While there are those who argue the CoP idea is undertheorised (see Fuller, 2007), others suggest that they are a social theory of learning itself that we learn via our interactions with other human beings, and importantly with the artefacts associated with that learning, such as books, computer programs and documents (Laskov, Mann, \& Dahlgren, 2008, p. 123). So, CoPs in practice and in theory are 'the basics building blocks of a social learning system because they are the social containers of the competencies that make up such a system' (Wenger, 2000, p. 229). Participating in a $\mathrm{CoP}$ formed to improve and reform assessment in the first-year space means that the competencies needed for this reform will be cooperatively defined by the CoP members. As such, the CoP model represents a process for creating communication, collaboration, learning and knowledge building through voluntary interactions between the members of the CoP. While CoPs do not have defined hierarchy or leadership roles, the implementation of the process does require a champion to promote the CoP and engage participants (Wenger, 1998; Wenger et al., 2002).

Successful CoPs should be based on the following three principles: mutual engagement members interact and respond to each other, developing norms and rules that guide engagement in the process; joint enterprise - the members understand the $\mathrm{CoP}$ and contribute to it, while simultaneously developing competencies needed within the CoP; and finally, a shared repertoire - of communal resources such as such as language and artefacts that members have access to and are competent in utilising (Laskov et al., 2008, p. 123; Tight 2007, p. 398; Wenger, 1998, p. 73). Higher education itself can be seen as a CoP, with many embedded CoPs within it, all with 'their own sense of joint enterprise, 
mutuality and shared repertoire' (Tight, 2007, p. 398). CoPs have been used as an effective approach for enhancing learning and teaching practice in higher education (McDonald \& Star, 2006; Nagy \& Burch, 2009; Viskovic, 2006). They can provide a space for sustained professional conversations around identified issues and valuable professional support for academics that are increasingly overwhelmed by continuous change, workload and research output demands (McDonald \& Star, 2006, 2008).

CoPs, in both theory and practice, are not without criticism. Wenger (2010, p. 6) argues that there is a lack of recognition of the influence of the institutional, political, or cultural context in which CoPs are situated. This is a significant critique given Ashwin's (2009) exhortation that 'the cultures of the institution in which the teaching-learning interaction is situated' (p. 10), is one of four key areas requiring scrutiny in higher education research. Hughes, Jewson, and Unwin (2007, p. 4) argue that there is a failure to conceptualise and account for the relationships of power which inform CoP development within social and institutional settings. And while the dominant emphasis in the literature on CoPs is that CoPs are egalitarian and harmonious joint enterprises, Wenger $(2010$, p. 8) insists that conflict can be a central part of the practice. In summary, CoPs are often analysed as individual enterprises within institutional and cultural settings, with little or no analysis of the forces or powers acting upon, or importantly, within those settings, that ultimately can influence both the processes of social learning that occur within the CoP, and the practical outcomes envisioned for the $\mathrm{CoP}$, in this case, reform of first-year assessment practices. What follows is a description of our experience with implementing a CoP at our university.

\section{The idea}

As mentioned previously, our project was developed to facilitate the review and enhancement of assessment practices across all first-year courses within our school through a CoP as a direct means of addressing the link between assessment and retention (Boud et al., 2010; Taylor, 2008). The project aims included improved assessment practices across potentially 16 first-year courses across both campuses of our institution, with the goal of improved retention across both. Additional aims included: build staff capacity, enhance collaboration across the academic and professional elements and ultimately, an enhanced learning and teaching culture.

\section{The plan - what we thought would happen}

Prior to the commencement of the CoP, a planning phase was undertaken to develop a process for carrying out the initiation and conduct of the CoP in line with Wenger's (1998) model of domain, community and practice. The domain identified was the link between the student experience, assessment and retention, while the community involved consisted of first-year course coordinators from across all first-year courses within our school. We also identified a number of other key stakeholders within the school, including the Dean of Teaching and Learning as a champion for the CoP, and a facilitator to support and manage the CoP process. The practice to be developed through the CoP was professional and collegial development to facilitate review and reform of assessment practices across all first-year courses within the school. 
For the conduct of the CoP, participants would attend regular CoP meetings where they would be introduced to the literature on the importance of effective assessment as part of an enhanced first-year experience. The intent was that their capacity would be built to engage as active participants in reflecting upon their own assessment practices so that they could be active agents in the review process of that assessment. In the design of this CoP, we were also mindful of the constraints of the higher education context, such as resources, workload and research demands (McDonald \& Star, 2006; Nagy \& Burch, 2009). To manage these constraints, we intended to provide financial support where possible in the form of marking buy-out and research assistance. These measures are consistent with those suggested by McDonald and Star (2006). We also sought to create a safe space for academics to express and share concerns about teaching constraints and institutional pressures.

\section{The progress and outcomes - what actually happened}

We now describe the implementation of the plan, and the progress and outcomes from the CoP process. To support our reflections on the efficacy of the CoP, we conducted follow-up interviews with a total of six (6) CoP participants. These interviews were conducted by the CoP facilitator who led the original project, and transcribed and analysed to identify themes in the interviewee's responses relating to their experiences of the CoP and its efficacy as a tool for reforming assessment practices. While we recognise data from six interviews may seem a small data sample upon which to base our analysis, the staff who participated in these interviews were present for each $\mathrm{CoP}$ meeting and were totally committed to the process. That their views on the CoP process are very similar, we argue, provide us with a coherent basis for our analysis, and validate our consternation about the impact of institutional pressures on the implementation of a CoP. We identify each interviewee via a numeric order of 1-6, which relates to the order in which they were interviewed.

To initiate the CoP process, all first-year convenors were invited by the CoP facilitator to attend an initial workshop. To further encourage participants, and highlight the commitment of the school executive to the process, the Dean of Teaching and Learning (as the CoP champion) also welcomed participants and gave assurance that the school saw value in staff contributing to the CoP. At the initial CoP workshop, we discussed the overall approach and strategy, with participants mutually engaged in designing the final approach for assessment review and reform. In this manner, the participants were identified as active agents in 'owning' the process and the project outcomes.

Initially, the response from participants was positive. Attendance at the initial CoP meeting was high and enthusiasm for the idea of a collegial, innovative approach to improvements in assessment was palpable. In expressing initial expectations for the CoP, one staff member stated:

I thought it would be a good opportunity to look more coherently at first year assessment structure. As it is, there is no scaffolding across courses, there is no coordination between academics on how people design their courses. I thought it would be great to sit down to look at assessment structures across all the first year course offerings and work together about what everyone was trying to achieve, and also learn from what others were doing. (Interviewee \# 3) 
Another staff member demonstrated enthusiasm around the opportunity to develop their own professional skills:

I was hoping for ideas for innovating with regards to assessment, new ways of doing things that improves the experience of students, teaching them what they need to know and then finding out if they had learnt and understood. (Interviewee \# 1)

Several institutional changes emerged at the same time as the CoP was getting off the ground, however, which dampened this initial receptivity. First, a Policy for the Standards for First Year Assessment was introduced in the same week that the first meeting was held. This was, in the words of Wenger (1998) an institutional artefact that crossed the CoP boundaries which would now need to be reinterpreted with the CoP domain. It was a formal university policy that related specifically to the content of the CoP domain, challenging the voluntary, collaborative approach to change in first-year assessment and making it an institutional imperative for staff to align their assessment with this policy. The reaction from the CoP champion and participants was that the CoP could still serve as a place where assessment reform could be addressed. Participants agreed that there was a need for consistency across assessment in the first-year space to meet the standards and support retention, and that the CoP could be a space to devise a good model to operate across the various first-year programmes.

After the initial meeting, however, CoP participants learnt that the decision to implement an institutional policy on assessment had been made with little or no staff consultation. As Nagy and Burch (2009, p. 242) argue, CoPs can be viewed by sceptical academics as a masquerade for a predetermined agenda that is really another committee. This was the view taken by some of the participants which did not augur well for the future progress of the CoP. As one participant stated about the policy for assessment, it is one of those changes that did not come from a collaborative space and resulted in a sense of more work and more responsibility' (Interviewee \# 2). Another felt that the change in agenda caused confusion among staff, stating the CoP 'became a vehicle for communicating policy rather than an open discussion about how best to improve first-year assessment from a grass roots collaborative level' (Interviewee \# 4). Another participant describes the impact on the progress and outcomes of the CoP:

It had a detrimental effect on what the CoP set out to achieve. Before it even began, these major constraints were placed on first year assessment and it affected the potential of the $\mathrm{CoP}$. The introduction of the policy inhibited the process. (Interviewee \# 5)

Two other institutional realities simultaneously emerged that served to likewise impede the sense of mutual engagement and shared repertoire necessary for successful CoPs. Atmosphere and morale within the school became negative over a withdrawal of sessional funding from all large first-year courses. Many saw this as a key indication of decrease in values given to teaching and learning issues. Academics felt overwhelmed and the victims of a non-caring institutional agenda that promoted excellence in teaching as rhetoric, while slashing funding for courses. The following comments from staff indicate the extent of staff disenchantment within the school and how it impacted their involvement in the CoP: 
This CoP ran the same year as sessional budget cut when everyone was upset, frustrated, in a bad mood. The CoP was trying to be implemented in a negative hostile environment. (Interviewee \# 6)

Because of decisions of the executive of the group in relation to the sessional budget I felt the pressure of time, lack of resources, and an unpleasant working environment. (Interviewee \# 5)

At the same time, a new rationalised Bachelor of Science Program was introduced. The rationalisation of degree programmes within the university sector has become commonplace (Cullen, Joyce, Hassall, \& Broadbent, 2003) with large first-year courses serving multiple degree programmes as an accepted pedagogical characteristic of higher education content delivery. The new programme meant increased workloads for many staff, and was seen by many to be unsound pedagogy. In addition, creating a collegial working group across the school was made difficult as the programme rationalisation involved several schools that had not previously worked together. Staff felt that they were under siege, and 'simmering resentment' (Ryan, 2012, p. 9) became the dominant emotion within the school, as evidenced by this comment from one staff member:

The institutional change, which isn't a problem in itself, but it was the way in which it was occurring, which was top down. It didn't involve listening to the views of the CoP or people who were committed to the first year experience and teaching. There was also an issue with emotions that came up as a result of this change. There was definite bitterness and anger towards the university administration, which are valid feelings, but very difficult to move beyond when there was no indication that these problems were being acknowledged. (Interviewee \# 3)

When asked if they would participate in future CoPs, participant views were mixed, with one participant stating: 'A more constructive and positive environment is required, and this relates to the atmosphere of the work environment in the group at large' (Interviewee \# 4). There was also some indication that that if the circumstances are right, CoPs can be a useful collegial tool to foster innovation and reform in the teaching/learning space:

I do think the CoP process can be useful. Even when desired outcomes aren't gained there in value in coming together to share concerns. There is still value in establishing the connections and relationships - that is the social capital for making benefits in the future. (Interviewee \# 5)

The initial aim of the CoP to improve assessment practices in first-year courses across the school through collaborative professional development of academics was compromised by the introduction of the artefact - the institutional policy on assessment standards - that crossed the CoP boundary - and was not reinterpreted favourably by the CoP members. Combined with wider institutional factors, this served to create an environment within the School where staff felt resentful, time poor and exhausted, with CoP members retreating from a sense of shared repertoire and joint enterprise which Wenger (1998, 2000) details are necessary for successful CoPs.

\section{Challenges and conflict in the higher education sector}

In describing our experience with implementing a $\mathrm{CoP}$ in the higher education context, we have detailed how this CoP was negatively impacted by internal institutional challenges, 
and the imposition of an artefact in the form of an assessment policy into the CoP boundary. We argue that the institutional culture evident within the school and the wider university is representative of sector-wide influences in higher education in Australia. Thus, the following section discusses the higher education sector more broadly with the view that the current institutional and cultural settings for higher education, and how power is distributed and managed within higher education, must be taken into account when analysing CoPs.

\section{The changing landscape of higher education in Australia}

There are those who believe that the current issues facing higher education are due to Australian universities being increasingly subject to, and embracing of, the fundamentalist logic of neo-liberalism (Curtis, 2013; Ryan, 2012). These issues include: increased managerialism and bureaucratisation, a sustained emphasis on greater efficiencies, compliance with auditing, quality and research measurements, an increased emphasis and measurement of 'quality' research outputs, together resulting in an academic environment characterised by an 'erosion of trust, an intensification of academic work, a decline in collegiality, threats to self-identity and feelings of alienation' and stress overall (Knight \& Trowler, 2000, p. 110).

Neo-liberal ideology assumes that freedom of the market is conducive to individuals' liberation and freedom (Harvey, 2007). This emphasis is derived from the neo-liberal belief that 'the market forces of a robust economy and the greater circulation of capital will [replace the state's need to] resolve social problems and inequities' (Sawyer \& Gomez, 2012, p. 26). Advocates of neo-liberalism demand that institutions be entrepreneurial, market-orientated, cost-effective and most of all, accountable (Ryan, 2012). These are the current demands placed upon higher education institutions.

Evidence of the influence of neo-liberalism in and on higher education can be seen in the wave of reforms in the higher education sector in Australia over the past 30 years that have resulted in an increasing deregulation and corporatisation of the university sector, marked by increased managerialism, greater efficiencies, compliance, quality and research measurements (Ryan, Guthrie, \& Neumann, 2008). Ryan (2012) argues that the latest wave of changes is accompanied by even more external and internal measurement, surveillance and control over universities and their academic workforce. There has thus been considerable pressure placed on Australian academic staff to be more competitive, productive and accountable, while simultaneously being more entrepreneurial and innovative. The increasing deregulation of the sector also means the institutions themselves must now operate in a much more highly competitive environment, and considerable pressure has been placed on them to strengthen management, to become more entrepreneurial and corporate-like (Meek, 2007).

Perhaps the most pressing indicator of the neo-liberalisation of higher education is the dominance of the research agenda in higher education in Australia (Chalmers, 2011), which has seen a demonstrable valuing of research over teaching quality. The value of research is becoming increasingly judged according to its capacity to demonstrate its immediate 'economic and social impact'. This focus on impact, outputs and measureable indicators (Curtis, 2013) is not conducive to staff engagement with activities that consume 
their time and energy, where these activities cannot be measured, quantified or assessed and given the same gravitas as research outputs.

These factors combined together are causing dissatisfaction among academic staff, with low morale among academic staff identified across many Australian higher education institutions (Bexley, James, \& Arkoudis, 2011; Coates et al., 2009). Universities and their permanent staff are under pressure to meet the performance criteria across all aspects of academic work, and the commentary on the intensification of academic work has been significant (Allport, 2000; Cashmore, Cane, \& Cane, 2013; Chalmers, 2011; D'Andrea, 2007). These factors together constitute as sector-wide impediments to across-institution collegial activity in general, and in particular, for engagement in collaborative and teaching focused professional development opportunities such as CoPs. Nagy and Burch (2009, p. 230), suggest 'the collegiate dimension to academic life appears to have been diminished by seeking the measurable, over the unquantifiable outcomes of collegiate relations'.

\section{Summarising the impact of institutional pressures on collegial learning processes}

We now offer an analysis of our CoP experience in light of the current institutional pressures impacting upon higher education. In describing the progress and outcomes of the CoP earlier in the paper, we identified a number of events that influenced the process. We also identified a number of issues that occurred as a result of these events, which impacted the efficacy of the CoP. While the timing and implementation of these institutional changes are specific to this particular context, we argue they are representative of events occurring in universities across Australia. We believe that the events that impacted the process of our particular CoP are related to wider institutional conditions, which in turn are driven by the neo-liberal shift in higher education. In short, wider issues of power and economy affected the institutional and cultural setting in which this particular CoP operated. We therefore concur with Ashwin (2009, p. 10) that the culture of the institution in which the CoPs is situated is of critical importance in any analysis of the CoP as a learning process, and with Wenger $(2010$, p. 10) that issues of power are inherent in a social perspective on learning, and that therefore power must be acknowledged in the analysis of such processes.

In summary, we identify three key institutional and neo-liberal driven forces that impacted upon our particular CoP process:

(1) Limited consultation and collaboration

The institutional changes that were happening during the time in which the CoP process was being implemented (sessional funding changes, assessment standards policy, etc.) were top-down mandates, with limited collaboration and communication with staff about their development and impacts. While Wenger, McDermott and Snyder argue that CoPs can create space to connect practitioner development to the strategy of the organisation (2002), in this case, the lack of staff consultation created an atmosphere of unrest among academic staff, with the sense of more work and more responsibility, with no support. The institutional conditions described here are representative of the neo-liberal focus on auditing, compliance and quality measures in higher education (Knight \& Trowler, 2000), which demands increased managerialism and limits 
collaboration. While the assessment standards policy in and of itself supports the transition pedagogy approach and a curriculum focus on assessment (Kift et al., 2010), the timing and implementation were driven by a focus on auditing and compliance, which created conditions of tension and disengagement.

(2) Atmosphere and morale within the school

In addition to limited consultation and collaboration around the introduction of the institutional changes during the $\mathrm{CoP}$ process, the efficacy of the $\mathrm{CoP}$ was also impacted by the low morale and negative atmosphere in the school. Participants in the CoP felt that there was a sense of bitterness among staff in response to the sessional funding cuts and the approach taken by the school to implementing new policy and programming. One participant identified the effect of communication and implementation on staff morale, claiming

this is where the break down happens, this causes disengagement and frustration of staff. It feels like there is no value of knowledge or respect for staff. It is a culture of bad/no communication and it is a process that is damaging. (Interviewee \# 6)

In conditions that are driven by market forces, the rationalisation of degree programmes becomes part of the neo-liberal approach to higher education (Cullen et al., 2003; Harvey, 2007). When such approaches are implemented through the institution with limited consultation, as seen in this case, morale can be significantly compromised, creating negative impacts on staff well-being and their willingness to be involved in change processes.

(3) Time, resources and participation

The constraints of time and resources are commonly cited by academics as barriers to engaging in new initiatives, given all the other expectations in the role (McDonald \& Star, 2006). In this case, academics felt that their efforts were thwarted by budget cuts to sessional funding, which made committing time to the CoP process very difficult. Participation in the CoP was also compromised by how participants perceived the school's attitude towards the value of teaching in light of the formal assessment policy. As one participant noted, 'there is a sense that people at the top don't trust the staff who are convening the courses and feel like they need to force them to do best practice'. This finding supports Viskovic (2006) and McDonald and Star's (2006) argument that without valuing individual contribution to the development of teaching practice, innovation will be limited.

We also found that academics are hesitant to commit to activities that have limited capacity to contribute to their research output. As stated by one CoP participant, 'the lip service to teaching needs to change, the reality is what the uni wants is research outputs and research grants. Teaching is at the bottom of the heap'. Such concerns are valid, as the outcomes of CoPs are difficult to measure (Nagy \& Burch, 2009), rather than research performance per se. The pressure academics feel around the dissonance between the value of teaching and research outputs can be seen as a reflection of the dominance of research outputs under a neo-liberal agenda (Curtis, 2013).

\section{Analysis}

Current research suggests that approaches that engage the whole institution are necessary to improve the first-year experience (Kift et al., 2010). The new policy on first-year 
assessment that was mandated at the outset of the CoP did take steps towards whole-ofinstitution reform regarding assessment. However, policy reform and implementation are an institutional activity which reflects wider cultural and institutional imperatives. It is not necessarily compatible with successful social leaning experiences such as CoPs. This was the conundrum faced by this CoP with its goal of assessment reform via a focus on mutual engagement and joint enterprise, and we argue, the potential conundrum of similar collaborative social learning approaches that seek to improve teaching and learning practices within the institution, and ultimately therefore, the student experience.

We argue that analyses of CoPs, which are in reality social learning experiences, must take into account the wider institutional and societal settings that inform and ultimately affect the experience of social learning that can occur in CoPs. While we have focused primarily on the power of structural and systemic realities that served to inhibit the social learning experience that was our CoP, following Ashwin (2009), we suggest that power can also be conceptualised as relational, 'that it plays out in different ways in different situations' (p. 22), and thus, that not all CoPs in all institutions will endure the same realities and outcomes. A focus of this paper was to highlight how the current higher education system contributes to the institutional and cultural reality of our institution, and how this impacted upon our CoP. As such, it may appear to privilege the role of structural and institutional power in the analyses of our CoP. We do not, however, want to totally dismiss the capacity for academic agency in the face of such structural forces, nor foreclose on the future utilisation of CoPs as a social learning experience in higher education, and conclude with the positive outcomes that did emerge from the CoP process.

The CoP created a safe space for academics to express and share concerns about teaching constraints and institutional pressures. This was highly valued by staff who participated, who felt that it created a community-focused medium for discussing such issues in which they had a voice. As one participant stated, 'the good thing about being there was an opportunity to share concerns, in some ways it was like a therapy session as we so rarely get a chance for that voice to be heard' (Interviewee \# 1). Thus, there was value obtained in establishing connections to build social capital for the future, which will be needed if the current proposed changes in higher education are realised.

\section{Conclusion}

This paper has delivered a narrative about events surrounding our attempts to establish a $\mathrm{CoP}$ focusing on reform and improvement of first-year assessment practices in first-year courses within our school. What has been revealed is the importance of scrutinising the institutional, cultural and structural factors in analyses of CoPs and similar social learning experiences. In this case, a specific combination of institutional factors, including policy, programme and budget changes, created an atmosphere that was not conducive for social learning activities like CoPs. These institutional realities were themselves informed by wider societal and structural issues, including the increasing pressure on management structures in higher education to conform to neo-liberal principles, with a focus on research outputs and impact, measurement and market forces (Curtis, 2013).

The current policy imperatives informing the Australian higher education sector render it problematic for those staff seeking to participate in social learning opportunities for learning about and improving their teaching practice. While many staff felt that the 
CoP was a valuable initiative, wider structural forces in higher education, and their effects on the culture of our institution, directly impacted upon the CoP process. The lessons learnt from this process show that deeper consideration of the context of higher education and its particular challenges is required when implementing a $\mathrm{CoP}$ in this setting, and in the analysing of such processes. This paper has documented the process of one such initiative to serve as a contribution towards understanding the issues associated with the current milieu in higher education, and its impact upon staff and their participation in CoPs.

\section{Acknowledgement}

I am grateful to two anonymous reviewers for their insightful feedback on an earlier version of this paper.

\section{Disclosure statement}

No potential conflict of interest was reported by the authors.

\section{Funding}

This work was supported by Griffith University Learning and Teaching Grants.

\section{References}

Allport, C. (2000). Thinking globally, acting locally: Lifelong learning and the implications for university staff. Journal of Higher Education Policy and Management, 22(1), 37-46. doi:10.1080/ 713678131

Ashwin, P. (2009). Analysing teaching-learning interactions in higher education: Accounting for structure and agency. London: Continuum International Publishing.

Bexley, E., James, R., \& Arkoudis, S. (2011, September). The Australian academic profession in transition: Addressing the challenge of reconceptualising academic work and regenerating the academic workforce. Melbourne: Centre for the Study of Higher Education, The University of Melbourne.

Boud, D., Freeman, M., James, R., Joughin, G., Sadler, R., Dochy F., et al. (2010). Assessment 2020: Seven propositions for assessment reform in higher education. Sydney: Australian Learning and Teaching Council.

Cashmore, A.M., Cane C., \& Cane, R. (2013). Rebalancing promotion in the HE sector: Is teaching excellence being rewarded? York: The Higher Education Academy.

Chalmers, D. (2011). Progress and challenges to the recognition and reward of the Scholarship of Teaching in higher education. Higher Education Research \& Development, 30(1), 25-38.

Coates, H., Dobson, I., Edwards, D., Friedman, T., Goedegebuure, L., \& Meek, L. (2009). The attractiveness of the Australian academic profession: A comparative analysis. Changing academic profession. Australian Council for Educational Research (ACER).

Commonwealth of Australia. (2014). Budget 2014-15 higher education. Commonwealth of Australia. Retrieved from March 13, 2014, http://www.budget.gov.au/2014-15/content/glossy/ education $/ \mathrm{html} /$ index.htm

Cullen, J., Joyce, J., Hassall, T., \& Broadbent, M. (2003). Quality in higher education: From monitoring to management. Quality Assurance in Education, 11(1), 5-14. doi:10.1108/ 09684880310462038 
Curtis, N. (2013). Thought bubble: Neoliberalism and the politics of knowledge. New Formations: A Journal of Culture/Theory/Politics, 80(80), 73-88. doi:10.1353/nfm.2013.0048

D'Andrea, V. (2007). National strategies for promoting excellence in teaching: A critical review. In A. Skelton (Ed.), International perspectives on teaching excellence in higher education: Improving knowledge and practice (pp. 169-182). Abingdon: Routledge.

Fuller, A. (2007). Critiquing theories of learning and communities of practice. In J. Hughes, N. Jewson \& L. Unwin (Eds.), Communities of practice: Critical perspectives (pp. 17-29). London: Routledge.

Griffith University. (2013). Griffith academic plan 2013-2017: Transforming the student experience. Retrieved from March 30, 2013, http://www.griffith.edu.au/about-griffith/plans-publications/ academic-plan

Harvey, D. (2007). A brief history of neoliberalism. Oxford: Oxford University Press.

Joughlin, G. (2009). Assessment, learning and judgement in higher education. Dordrecht: Springer. Kift, S., \& Nelson, K. (2005). Beyond curriculum reform: Embedding the transition experience. In A. Brew \& C. Asmar (Eds.), Higher education in a changing world: Research and development in higher education (pp. 225-235). Milperra: HERDSA.

Kift, S., Nelson, K., \& Clarke, J. (2010). Transition pedagogy: A third generation approach to FYE A case study of policy and practice for the higher education sector. The International Journal of the First Year in Higher Education, 1(1), 1-20.

Knight, P., \& Trowler, P. (2000). Editorial. Quality in Higher Education, 6(2), 109-114.

Krause, K-L., Hartley, R., James, R. \& McInnis, C. (2005). The first year experience in Australian universities: Findings from a decade of national studies. Canberra, Australia: Australian Department of Education, Science and Training. Retrieved from February 24, 2009, http:// www.griffith.edu.au_data/assets/pdf_file/0006/37491/FYEReport05.pdf

Laskov, K.B., Mann, S., \& Dahlgren, L.O. (2008). Developing a community of practice around teaching: A case study. Higher Education Research \& Development, 27(2), 121-132.

McDonald, J., \& Star, C. (2006, December 6-8). Designing the future of learning through a community of practice of teachers of first year courses at an Australian university. In The first international LAMS conference: Designing the future of learning. Sydney, Australia.

McDonald, J., \& Star, C. (2008, July 1-4 ). The challenges of building an academic community of practice: An Australian case study. Paper presented at the proceedings of the 31st HERDSA annual conference: Engaging communities (HERDSA 2008), Rotorua NZ.

Meek, V.L. (2007) 'Internationalisation of the academic profession in Australia'. In M. Kogan \& U. Teichler (Eds.), Key challenges to the academic profession (pp. 65-80). Paris: UNESCO.

Nagy, J., \& Burch, T. (2009). Communities of practice in academe (CoP-iA): Understanding academic work practices to enable knowledge building capacities in corporate universities. Oxford Review of Education, 35(2), 227-247. doi:10.1080/03054980902792888

Oliver, R. (2012, June 28). Using technology to engage and support learners in the transition to university. Proceedings. The International First year in Higher education Conference. Brisbane Australia. Retrieved from March 30, 2013, http://www.fyhe.com.au/past_papers/papers12/ Papers/keynote_oliver.pdf.

Richlin, L., \& Cox, M.D. (2004). Developing scholarly teaching and the scholarship of teaching and learning through faculty learning communities. New Directions for Teaching and Learning, 2004 (97), 127-135. doi:10.1002/tl.139

Riddle, S., Schmidt, B., Chapman, B., Zyngier, D., Byrne, E., Turner, G., et al. (2014, May 13). Federal budget 2014: Education experts react. The Conversation. Retrieved from June 30, 2014, http://theconversation.com/federal-budget-2014-education-experts-react-26649

Rust, C. (2002). The impact of assessment on student learning. Active Learning in Higher Education, 3(2), 145-158. doi:10.1177/1469787402003002004

Ryan, S. (2012). Academic zombies. Australian Universities Review, 54(2), 3-11.

Ryan, S., Guthrie, J., \& Neuman, R. (2008). 'Australian higher education transformed: From central coordination to control' in ed. C. Mazza, P. Quattrone and A. Riccaboni, European universities in transition: Issues, models and cases (pp. 171-87). Cheltenham, UK: Edward Elgar. 
Sawyer, S., \& Gomez, E.T. (2012). On indigenous identity and a language of rights. In S. Sawyer \& E. T. Gomez (Eds.), The politics of resource extraction: Indigenous peoples, multinational corporations, and the state (pp. 9-32). Palgrave Macmillan.

Taylor, J. (2008). Assessment in first year university: A model to manage transition. Journal of University Teaching \& Learning Practice, 5(1). Retrieved from March 30, 2014, http://ro.uow. edu.au/cgi/viewcontent.cgi?article=1059\&context=jutlp

Tight, M. (2007). Research into higher education: An a-theoretical community of practice. Higher Education Research \& Development, 23(4), 395-411.

Viskovic, A. (2006). Becoming a tertiary teacher: Learning in communities of practice. Higher Education Research \& Development, 25(4), 323-339. doi:10.1080/07294360600947285

Wenger, E. (1998). Communities of practice: Learning, meaning, and identity. Cambridge, MA: Harvard Business School Press.

Wenger, E. (2010). Communities of practice and social learning systems: The career of a concept. In C. Blackmore (Ed.), Social learning systems and communities of practice (pp. 179-198). Milton Keynes: Springer Verlag and the Open University.

Wenger E. (2000). Communities of practice and social learning systems. Organization, 7(2):225246.

Wenger, E., McDermott, R., \& Snyder, W. (2002). Cultivating communities of practice: A guide to managing knowledge. Cambridge, MA: Harvard Business School Press.

Wilson, K., \& Lizzio, A. (2011). Facilitating commencing students' success with early assessment. Sydney: Australian Learning and Teaching Council. 


\section{Good CoPs and bad CoPs: facilitating reform in first-year assessment via a Community of Practice}

\section{Catherine Howlett, James Michael Arthur \& Jo Anne Ferreira}

To cite this article: Catherine Howlett, James Michael Arthur \& Jo Anne Ferreira (2016): Good CoPs and bad CoPs: facilitating reform in first-year assessment via a Community of Practice, Higher Education Research \& Development, DOI: 10.1080/07294360.2015.1137881

To link to this article: http://dx.doi.org/10.1080/07294360.2015.1137881

\section{Published online: 19 Feb 2016.}

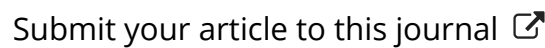

Џll Article views: 6

Q View related articles $匚$

View Crossmark data 